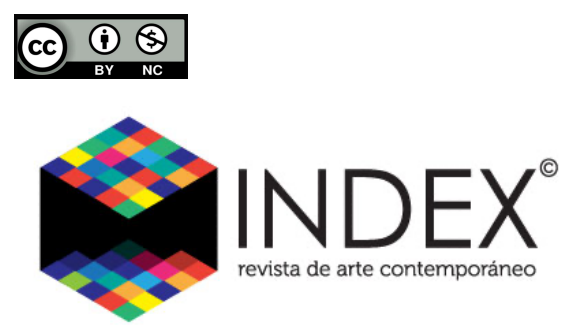

No. 11. MAY 2021

ISSN: 2477-9199

\author{
Temas del arte
}

DOI: $10.26807 /$ cav.vi11.405

\title{
ARCHIVO EL TELÉGRAFO: PRÁCTICAS PEDAGÓGICAS Y ARTÍSTICAS EN LA UARTES
}

\section{EL TELÉGRAFO ARCHIVE: PEDAGOGICAL AND ARTISTIC PRACTICES AT UARTES}

Janina Suárez-Pinzón

\section{Resumen}

Análisis del trabajo realizado por el colectivo de investigación Otras Derivas DIY en el fondo documental del periódico más antiguo del Ecuador. Durante el periodo 2018 - 2020, siguiendo una metodología de cadáver exquisito, el grupo dio valor a lo procesual en la búsqueda de una narrativa que promoviera la filosofía Do It Yourself entre la comunidad de la Universidad de las Artes. El Archivo El Telégrafo fue protagonista de prácticas pedagógicas a través de talleres abiertos guiados por artistas invitados donde se entrecruzaron fotografía, video, collage y dibujo. La trayectoria fue desde lo analógico hacia lo digital, arrancando con la estética fanzinera para llegar a la descontextualización de textos y fotografías, luego vino una mirada crítica y creativa de la visualidad para entender la saturación cotidiana de las imágenes y el (re)aparecer de lo que reposa en latencia. Como resultado del grupo está la exhibición Mapeando el Archivo. 
Palabras claves: archivo, metodologías artísticas, fondo documental, hemeroteca, DIY.

\begin{abstract}
This analysis is made from the working group «Otras Derivas DIY» in the documental collection of the oldest Ecuadorian newspaper. Between 2018 and 2020, using an exquisite corpse methodology, the working group enhance the importance of the process in the search of a narrative that promotes the "do it yourself» philosophy within the UArtes community. El Telegrafo's archives launched pedagogical practices through open workshops guided by guest artists; where photography, video, collage, and drawing were intertwined. It was driven from the analogical to the digital, starting with the fanzine aesthetics for texts and photographs decontextualization, moving to a critical and creative gaze of visuality to comprehend daily images saturation. "Mapping the archives» is a result of this working group.
\end{abstract}

Keywords: archive, artistic methodologies, documentary collection, newspaper archive, DIY.

\title{
Biografía de la autora
}

Janina Suárez-Pinzón (Guayaquil, 1981). Docente e investigadora de la Universidad de las Artes - Ecuador, entre los proyectos colectivos que está involucrada constan: Otras Derivas DIY, Amorfino para la difusión de la cultura montuvia mediante una reflexión de su geopoética regional, y Abriendo la puerta: espacios de articulación entre Pedagogía-PolíticaArte y Comunidad. Coordina el Grupo de Trabajo de CLACSO “Artes, educación y ciudadanía” 2019-2022 a través del Instituto Latinoamericano de Investigación en Artes (ILIA) en conjunto con la Universidad Nacional de Artes- Argentina. Es candidata doctoral en Sociología por la Universidad de Coimbra - Portugal, su tesis explora a los grupos de teatro universitario de Guayaquil para reflexionar sobre procesos creativos colectivos y la figura del 
amateur. Es máster en Comunicación y Creación Cultural y se formó como Periodista Profesional.

Código de identidad ORCID: https://orcid.org/0000-0002-3418-0375

\section{Percibir al Archivo maleable o interminable}

El proyecto colectivo de investigación Otras Derivas DIY pensó en los conceptos de archivo, historia y memoria, articulados en los circuitos de auto-producción y auto-edición de conocimiento que se iban retroalimentando progresivamente por las trayectorias formativas particulares, así también democratizando el uso de las tecnologías que servirían para desimbricar, refuncionalizar y reactivar el Archivo El Telégrafo ${ }^{1}$ del que la Universidad de las Artes (UArtes) es depositaria.

Archivo El Telégrafo es un espacio de poder en el que se da visibilidad y relevancia a ciertas problemáticas sociales, de igual manera, es un patrimonio donde se conservan experiencias e historias colectivas de Guayaquil. Este Archivo salta las lógicas de la privatización del saber para tornarse accesible a la ciudadanía; al encontrarse en una biblioteca pública se deja absorber por esquemas y clasificaciones propias de un fenómeno bibliotecológico. Dicha situación puede ser ventajosa para quienes desde la academia, intentamos hacer una reescritura de lo común, promoviendo su uso y socialización de formas de producción. A la vez que podría ser una amenaza cuando aparecen tensiones con las políticas institucionales de la UArtes, lo que conlleva a que El Telégrafo se vuelva un archivo represado y apartado para la comunidad universitaria.

En su apogeo, en la década de los noventa, El Telégrafo era el medio que ofrecía la versión oficial de la historia, el que determinaba los contenidos relevantes para las portadas y el que definía la permanencia de esos hechos en la memoria de sus lectores. Era una fuente

\footnotetext{
${ }^{1}$ http://biblioteca.uartes.edu.ec/inicio/espacios/fondo-el-telegrafo/\#
} 
confiable que desde la solidez de su investigación periodística señalaba los aspectos noticiosos prioritarios y los actores influyentes para el debate en la sociedad. El Telégrafo guiaba la interpretación de los sucesos para que la ciudadanía pudiera comprender de mejor manera lo que ocurría en su entorno. La redacción y el estilo de las noticias evidenciaba los intereses políticos que estaban en riesgo en el Ecuador, por lo que deducimos que la información es susceptible de encubrir propaganda o sensacionalismo. Un ejemplo son las notas contadas desde la perspectiva del funcionario público y de su labor burocrática, es decir que el mensaje entrelíneas fomentaba aspectos positivos de las obras gubernamentales, resaltando así la imagen de un Estado preocupado por el bien común. Aquí cabe pensar en Eric Ketelaar (2003) cuando refiere que los archivos tienen una singularidad intrínseca dada su "envoltura contextual", constituida por la unicidad de los procesos y funciones que produjeron registros y por el contexto de otros documentos creados por la misma actividad a lo largo del tiempo.

En lo concerniente a los límites del Archivo alertamos que los ejemplares actuales del periódico que estuvo en circulación hasta julio de 2020 reposan en la nube respaldados en formato PDF, sin que necesariamente migren en físico hacia la colección patrimonial. Las ediciones disponibles para consulta van desde el año 1900 al 2012. Este gesto de desarraigo repercute en la identidad institucional, al hacerse a un costado o al dejar algo fuera del archivo oficial se paraliza su fluido, nos preguntamos entonces cómo cierta información alcanza la categoría de coleccionable. Destacamos que una vez que entró en liquidación la Empresa de Medios Públicos EP de la que El Telégrafo hacía parte pasó a ser un diario digital en aras de evitar su desaparición.

El Archivo está en la dicotomía de lo homogéneo y lo heterogéneo pues se encuentra desperdigado en los pisos de la Biblioteca de las Artes. Existe una bóveda con los tomos empastados, un cuarto donde están los archivadores que contienen una parte de las fotos impresas y de los negativos y un sector de perchas donde constan las cajas catalogadas con material generado por los reporteros gráficos en las coberturas periodísticas. En febrero de 2019 cuando se inauguró oficialmente el Archivo, una noticia publicada por El Telégrafo² explicó:

\footnotetext{
2 Archivo de EL TELÉGRAFO, listo para hacer consultas. 2 de marzo de 2019. Redacción Cultura.
} https://www.eltelegrafo.com.ec/noticias/cultura/10/archivo-eltelegrafo-consultas 
"Se conservan las imágenes de 1930-1989; en slides, las de 1990-1995; de 1995-2005, en negativos, y las de 2006-2012, en discos compactos (...) A partir de los noventa, las imágenes fueron organizadas por temáticas; en lugar de archivarlas por orden cronológico (...) Así, por ejemplo, las cajas marcadas con el código 2.2.6 contienen imágenes relacionadas a la Función Legislativa".

Otras Derivas DIY dispone de productos visuales logrados a través de la digitalización de algunos tomos y de las imágenes del Archivo, igualmente el proceso investigativo nos sirvió para explorar creativamente dichos materiales. Aclaramos que no era nuestra intención seguir ningún parámetro de digitalización técnica para una catalogación profesional del Archivo ni mucho menos para inventariar o tener control del acervo y de sus colecciones hemerográficas o fotográficas. Lo que quizá nos distanció del trabajo de un investigador de la historia según lo descrito por Hidalgo (2017):

Conlleva a realizar una búsqueda exhaustiva en el caso de fuentes primarias, ya que estas se encuentran dispersas y en peligro de desparecer por un inadecuado manejo de los repositorios públicos en el país y falta de políticas públicas para garantizar la existencia, preservación y puesta en valor del patrimonio documental. (p. 20)

Tal vez en nuestras derivas investigativas seguimos los pasos del artista suizo Thomas Hirschhorn al romper con el orden jerárquico de las obras y olvidar el lugar de inicio que tiene un archivo. En los dos años de duración del proyecto se invitó a la interacción para que la comunidad universitaria pudiera penetrar en los documentos a partir de las pistas que íbamos seleccionando aleatoriamente. Al impulsar la idea de "hazlo tú mismo" era tácito que no queríamos una alfabetización ni tampoco caer en totalitarismos al pensar que los contenidos de El Telégrafo son todo lo que existe y debe saberse o son todo lo verdadero, sino que dábamos la potestad para que las personas atribuyan sus sentimientos, creencias y deseos poniendo en primer plano una retórica inédita. Desde luego, no éramos inocentes de lo que implica una tarea investigativa a través de la prensa, como lo expone Tamayo (2018): 
Consiste en desentrañar si la información entregada apuntala un fin determinado o un objetivo en particular que beneficie a algún sector dentro de la sociedad; si la intención de un medio de comunicación en particular es apoyar un determinado sector político o económico, o beneficiar determinados intereses. Y para ello es necesario verificar la producción noticiosa, la intención informativa, la orientación de la opinión, así como la publicidad que sustenta el ingreso que permite el funcionamiento del medio. (p. 142)

Estábamos interesados en un ethos estudiantil, en productores-consumidores animados al prototipado para dar rienda suelta en sus pericias, para que el Archivo resultara atractivo y que el estudiantado pudiera apropiarse de símbolos en sus bosquejos, textos descriptivos o ensayos. Indudablemente temíamos fracasar en la acogida de los cuatro talleres que organizamos entre agosto de 2018 y enero de 2019 pues eran intensivos que duraban un fin de semana, lo que demandaba el compromiso de las personas inscritas.

Como equipo de investigación debíamos precautelar la documentación de Otras Derivas DIY generando un archivo personal, lo que significaba recursos materiales, económicos y humanos; necesitábamos decidir y llegar a consensos para que pudiéramos conservar la información en discos duros o almacenar gratuitamente en carpetas One Drive y así poder interpretarla desde nuestras bitácoras, plataforma abierta Moodle o in situ durante la temporada de los talleres, todo ello era vestigio de la experiencia pedagógica y de la sistematización de cómo fuimos manipulando, contextualizando y problematizando las partes del Archivo El Telégrafo. De igual modo, íbamos articulando registros, soportes y saberes para nuestra creación artística, por lo que nuestro comportamiento puede equipararse con el del "nuevo memorialista”, término acuñado por Anna Guasch (2012), al probar nuevas maneras de llegar a unas historiografías alternativas que nos afiancen con el pasado.

\section{Prácticas pedagógicas - Talleres abiertos UArtes}

En Otras Derivas DIY nos preguntábamos ¿đde qué manera se podrían implementar procesos para desarrollar la creatividad a partir de las ideas de memoria y archivo con el estudiantado de la UArtes? Nuestra meta era lo procesual pues consideramos que a través de la 
práctica artística se hallaría una narrativa conjunta en la que estudiantes-participantes promoverían una filosofía Do It Yourself(DIY), de forma tal que lo co-creativo expandiera una comunidad capaz de autodeterminarse en su relación con los espacios de producción. Y dicha comunidad tomaría el control en la creación desde una participación activa motivada por interacciones gratificantes con otros artistas donde asimismo, se estimularía la comprensión y familiaridad con nuevos saberes y formatos de obras.

Durante el primer año se contempló una sinergia con la asignatura Taller Transdisciplinar impartida en la Nivelación ${ }^{3}$, sabiendo que era un espacio donde ensayaríamos estrategias para imaginar, describir, producir y gestionar alrededor de textos, objetos e imágenes. El propósito era develar nociones de identidad y género al reinterpretar el contenido del periódico guayaquileño, a través de prototipos o del ensamblado de piezas escultóricas; en paralelo pusimos en marcha un Moodle para socializar las bitácoras y promover colaboraciones, intercambios y auto-investigaciones de las personas involucradas. Esa fue la tentativa metodológica para auto-producir y acercarnos a las nuevas tecnologías, de esta forma reafirmamos que en el Archivo El Telégrafo ningún documento tiene un significado fijo, lo que nos evoca a lo dicho por Sue Breakell (2008): "podemos conocer la acción que creó el rastro, pero sus significados presentes y futuros nunca pueden ser fijados”.

Otras Derivas DIY, ganador del Primer Concurso de Proyectos de Investigación 2018 2019 de la UArtes, facilitó el encuentro de docentes de diferentes áreas de conocimiento para indagar métodos procesuales al habitar el Archivo El Telégrafo. Así nos juntamos Cristian Villavicencio, Aurora Zanabria, Juan Carlos Fernández “El Mago”, artistas con trayectoria en la fotografía, curaduría, pintura, arte conceptual y diseño gráfico, mientras que yo, Janina Suárez Pinzón, contribuía desde mi formación periodística. Internamente, los integrantes de esta

\footnotetext{
${ }^{3}$ En este departamento de la UArtes se matriculan al menos 200 aspirantes distribuidos en las carreras de Cine, Creación Teatral, Danza, Literatura, Producción Musical, Artes Sonoras y Artes Visuales, prevaleciendo las inscripciones en ésta última. El Taller Transdisciplinar, es una de las ocho asignaturas que se dictan durante el semestre, posibilita al estudiante procesos de creación que revelen sus capacidades y habilidades para desarrollar propuestas que cuestionen y transgredan los marcos disciplinares, y que interpretan nuestra realidad sociocultural.
} 
investigación nos planteamos trabajar con la metodología "cadavre exquis" (cadáver exquisito) contextualizada a las prácticas contemporáneas, en nuestra creación colectiva los aportes individuales modelaron los resultados parciales y finales del proyecto. En nuestro proceso fue fundamental el apoyo de Reinaldo Rodriguez, custodio del Archivo, quien trabajó 21 años en El Telégrafo.

Para el acercamiento al Archivo recurrimos a estrategias de experimentación pedagógica, tecnológica y artística que se cristalizaron en cuatro talleres y en la exposición Mapeando el Archivo. El primero de los talleres fue de fanzines con José Luis Jácome, el segundo llamado Interrogar al Archivo con François "Coco" Laso, el tercero de <scannerpack>el_telégrafo con Karla Tobar y el cuarto taller de retroconceptualización gráfica con Javier Pérez. Con los talleres potenciamos el sentido de pertenencia en la comunidad UArtes y animamos al estudiantado en la construcción de relatos que entrecrucen fotografía, video, collage y dibujo. Asimismo, cada taller nos sirvió para acumular una base conceptual para nuestra indagación del trabajo en red, en cambio la exposición fue el punto culminante como makers.

\section{Taller de Fanzines}

En agosto de 2018, una veintena de estudiantes y docentes de la UArtes trabajaron junto al artista ambateño José Luis Jácome del Colectivo Central Dogma en la confección de fanzines a base de recortes y fotocopias de El Telégrafo obtenidas de los tomos del periódico del año 1930. En el proceso creativo nada fue censurado, las composiciones poéticas y los collages sobresalieron en la autoproducción. Cada participante tenía libertad de jugar y deformar imágenes o textos, sacándolas de contexto para crear un lenguaje surrealista o mensajes conforme su estilo y personalidad, como comenta Jácome (2019):

Con los materiales elaborados por cada uno de los participantes, realizados en diferentes formatos, procedimos a fotocopiar los originales, generando así la publicación serial fotocopiada tipo fanzine con contenidos mixtos de las experiencias individuales más los aportes del brainstorming de ese día y los materiales recopilados de archivo que generaron un contenedor en una caja de 
cartón de 30 x 30 centímetros impresa con la técnica del esténcil y graficada por uno de los estudiantes de la UArtes. (p.1)

Esta experimentación facilitó la construcción de nuestra versión de una fanzinoteka e indirectamente afianzó la conexión entre el estudiantado. Al respecto, Jácome (2019) describió es la manera en la que generamos nuestro archivo, en diferentes volúmenes, que contiene múltiples espacialidades y temporalidades, muy similar a un archivo institucional, pero al mismo tiempo es un documento inspirado en la creación colectiva, la necesidad de generar memoria a través de metodologías que devienen de otras derivas del arte contemporáneo y las prácticas sociales (p.1).

Fue placentero para el equipo de investigación saber que Jácome ganó la Convocatoria Pública para Proyectos Artísticos y Culturales 2018 - 2019, impulsada por el Instituto de Fomento de las Artes Innovación y Creatividades (figuras 1 y 2). Su proyecto denominado Archivomancia comprendía la identificación, recopilación y digitalización de archivos gráficos, libros y recursos audiovisuales de El Telégrafo. La archivomancia se basaba en el trabajo del cabalista extásico Abraham Abulafia, quien determinó niveles de (re)interpretación al fijarse en la intertextualidad, las alegorías de los textos o los errores gráficos que permiten percibir el sentido oculto y las historias inéditas de un archivo.

Jácome editó un libro memoria de su proyecto en el cual escribí un texto titulado Las Otras Derivas del Archivo donde señalo que en el taller de fanzines aparecieron técnicas de Abulafia como el cut-up puesto que en la yuxtaposición de imágenes se permitió una nueva lectura, una reestructura de los significados sorteando el control entre talleristas, quienes a su vez no buscaban una interpretación literal ni se preocupaban del contexto del documento aunque les causaba sorpresa la vigencia de las noticias en los tiempos actuales (Suárez, 2019, p.11). 

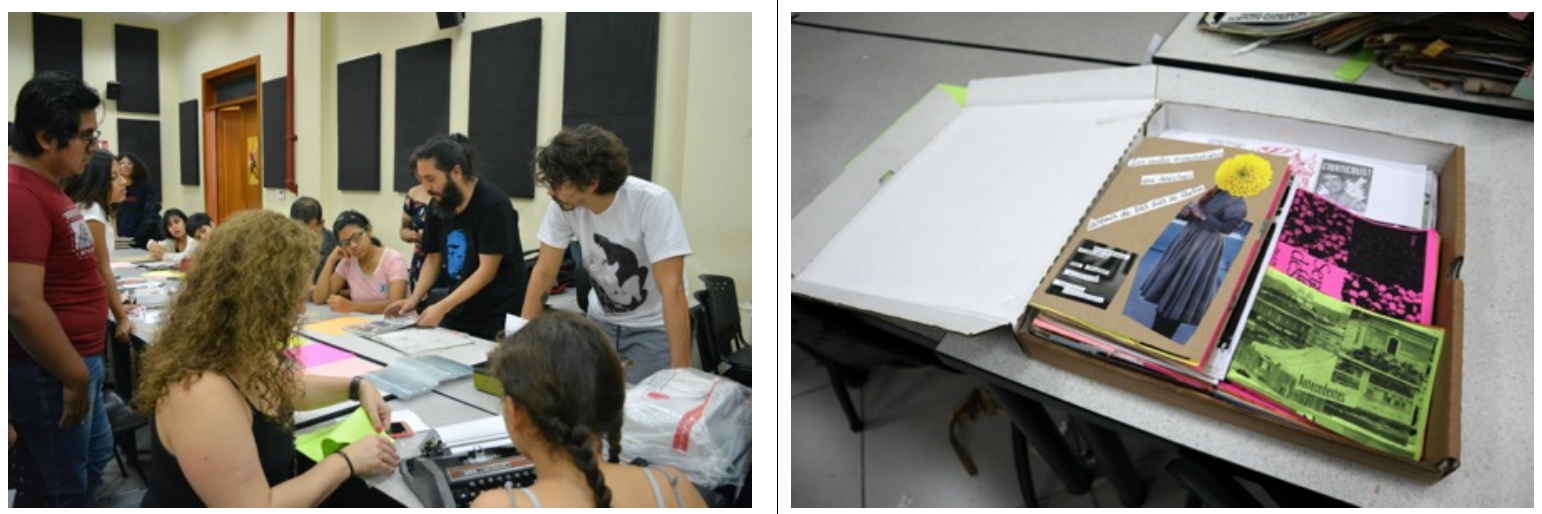

Figura 1 y 2. El artista José Luis Jácome mostrando su colección da fanzines y la fanzinoteka que produjeron los talleristas en la UArtes. Fotografías Otras Derivas DIY.

\section{Taller Interrogar el Archivo}

Siendo la creación colectiva el detonante, se propusieron otros talleres durante la investigación para generar proximidad con la materialidad del Archivo, la segunda experimentación, a fines de noviembre 2018, tuvo al artista François “Coco” Laso, quien propuso interpelar la memoria en un trabajo con documentos iconográficos y textuales desde los cuales se posibilitaba un resurgir o reaparecer de lo oculto, aquello que reposa en la latencia. Inclusive (re)pensar que no es necesario poseer un estatus privilegiado para acercarse a la historia, sino que es posible poner en duda documentos-prueba de la historia oficial cuya combinación foto-palabra son solo un síntoma de traumas o de mentiras construidas para ocultar o borrar a otros. Al liberar el acceso y al consentir que las personas se pierdan en los archivos como en El Telégrafo, éstas avivan una memoria insumisa.

Cuando el equipo invitó a Laso teníamos en mente su trabajo sobre la matanza de trabajadores del ingenio azucarero Aztra, el que se vio reflejado en la instalación Un Martes Cualquiera, ganadora del Nuevo Premio Nacional de Arte Mariano Aguilera 2017-2018. Su obra es una crítica y un homenaje para despertar la memoria y hacer aparecer al proletariado que reclamaba mejoras salariales y condiciones laborales. El interés de Laso, como lo explica la curadora de la instalación, Ana Rodríguez (2018), era resaltar la ausencia de los cuerpos por eso 
creó un mural de papel de caña con imágenes amplificadas de esas víctimas, mayormente de origen indígena, para dar cuenta de la violencia que nos acecha.

En este taller se buscó retornar a lo reprimido en el Archivo El Telégrafo cual acto performático que transforma al objeto-documento para producir una nueva realidad socialvisual-textual. Desde unos ejes de intervención, circunscritos en plazos, donde a los talleristas se les interpeló sobre las implicaciones éticas y estéticas de extraer la materia o el material de la memoria. La acción efímera con el mural expuesto en el espacio público revivía al Archivo no con una intencionalidad nostálgica sino cuestionándole con cierta irreverencia la información que proporcionó el periódico en su época de auge (figuras 3 y 4).
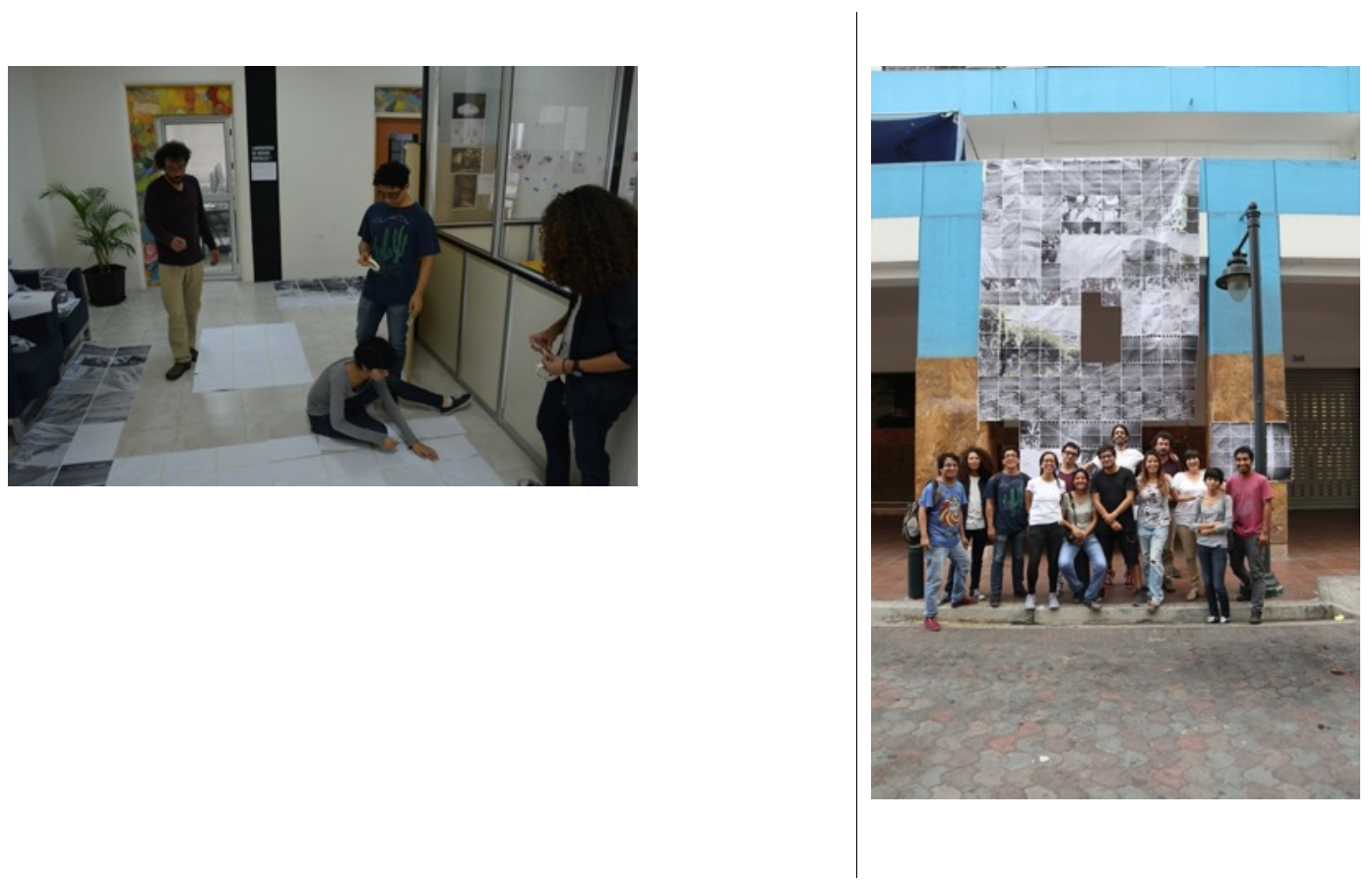

Figura 3 y 4. El mural colaborativo mostraba una composición azarosa de imágenes editadas por los talleristas. La obra fue colgada en los exteriores del edificio de Correos del Ecuador, sede de la UArtes. Fotografías Otras Derivas DIY.

\section{Taller Scanner-pack}


La artista Karla Tobar compartió su proyecto <scanner-pack>bilbao-linz_travelbook, originado en el ańo 2016; es un kit de registro DIY que consta de un escáner obsoleto, antena, raspberry pi y un módulo GPS que sirve para crear formas poéticas y posibilidades de expresión artística. En este proyecto han participado trece artistas para hablar de su ciudad o de un archivo en la interacción del cuerpo en movimiento con un dispositivo lumínico. Las propuestas de escaneo y de registro variaron desde las intenciones o visiones de los artistas y han permitido que Tobar tenga un gran banco de imágenes geolocalizadas.

En el website de Fundación BilbaoArte Fundazioa se divulgó que "<scanner-pack> se basa en la Proxémica (Edward T. Hall, 1963) entendiendo la forma en la que percibimos la distancia como condicionada culturalmente en cada persona o como un límite invisible que marca un espacio personal. Esta propuesta reduce la distancia entre el espacio privado con un área más lejana y pública registrando esta invasión espacial como un acto de dinámicas personales e interpersonales entre el cuerpo humano y lo que le rodea".

En nuestro taller pudimos generar escenas y relatos con las capturas hechas desde el escáner portátil, esos materiales facilitaban una reconstrucción o deconstrucción de significaciones. En cada turno, los talleristas frotaban el scanner pack en diferentes superficies de los rincones del Archivo El Telégrafo, el dispositivo tenía que ser presionado por algunos minutos para el procesamiento de las imágenes, por ello debíamos actuar cuidadosamente al manipular ciertos tomos donde el papel envejecido se deshacía ante cualquier intento de lectura (figuras 5 y 6). 


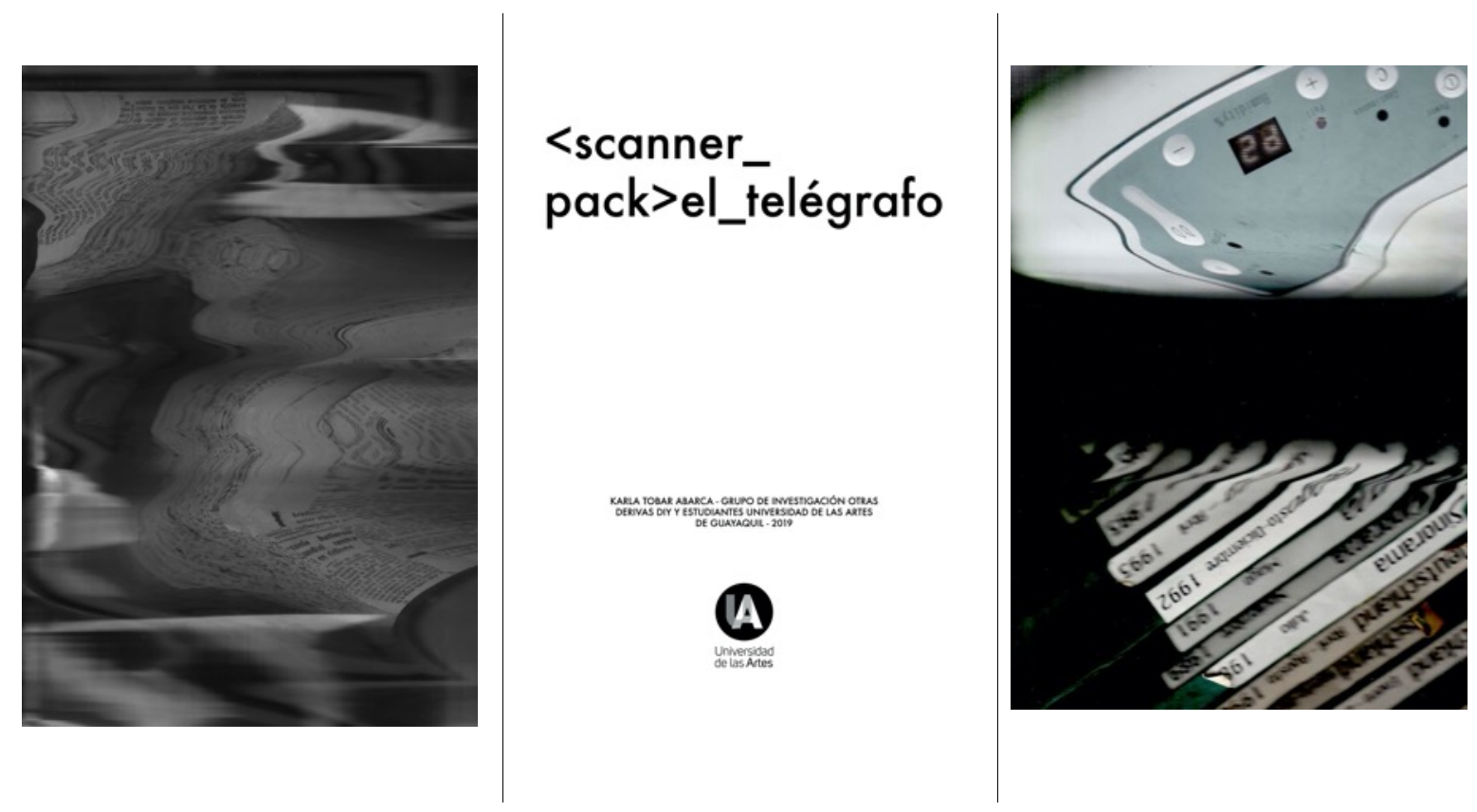

Figura 5 y 6. Páginas del libro colaborativo que resultó del taller con la artista Karla Tobar donde usamos un dispositivo óptico para intervenir el Archivo El Telégrafo. Fotografías Otras Derivas DIY.

\section{Taller Retroconceptualización Gráfica}

El último taller que se programó en enero de 2019 tuvo como invitado al artista Javier Pérez, alias@cintascotch, quien compartió una metodología de la ilustración contemporánea que consistía en la combinación de objetos cotidianos con dibujos sencillos para generar imágenes sorpresivas. Las pautas de Pérez apuntaban a que se debe pensar menos en sobrepasar las cosas para la creación de nuevos conceptos, sin importar nuestras habilidades es necesario escuchar frases o pensamientos de momentos valiosos porque la inspiración sucede en segundos. Aunque podían parecer pautas elementales son las que le permiten a él crear diariamente ilustraciones, campañas publicitarias o cortometrajes.

Con esta jornada se reflexionó sobre la saturación de las imágenes mediante una mirada crítica y creativa de la visualidad de El Telégrafo. Además el abordaje gráfico promovió un trabajo minimalista en el cual los talleristas autocompletaban con diseños propios las 
fotografías de diversos objetos presentes en publicidades u otros relatos del periódico. En el marco (tamańo post card) se podían combinar elementos para formar una composición visual provocadora, en escala de grises. Al crear su ficción los talleristas contaban una historia con un significado diferente facilitando la comprensión de un tema específico.

En los debates internos del equipo de investigación, Juan Carlos Fernández "El Mago" nos decía que enfrentarnos a ilustraciones concertadas por @cintascotch posibilita observar desde otra orilla una carga simbólica y reflexiva de una mirada gastada, debido a que su tipo de ilustración zigzaguea entre el minimalismo, arte conceptual, dadaísmo o el dibujo infantil, rompiendo con la ceguera provocada por un estallido de imágenes en la contemporaneidad. Esto quiere decir que Pérez usó una método híbrido que osciló entre la observación, reflexión y aleatoriedad para inducir a los talleristas a dejarse atrapar por la singularidad de imágenes cotidianas para en una segunda instancia construir mediante dibujos determinantes una especie de gráfica atemporal (figura 7 y 8 ).
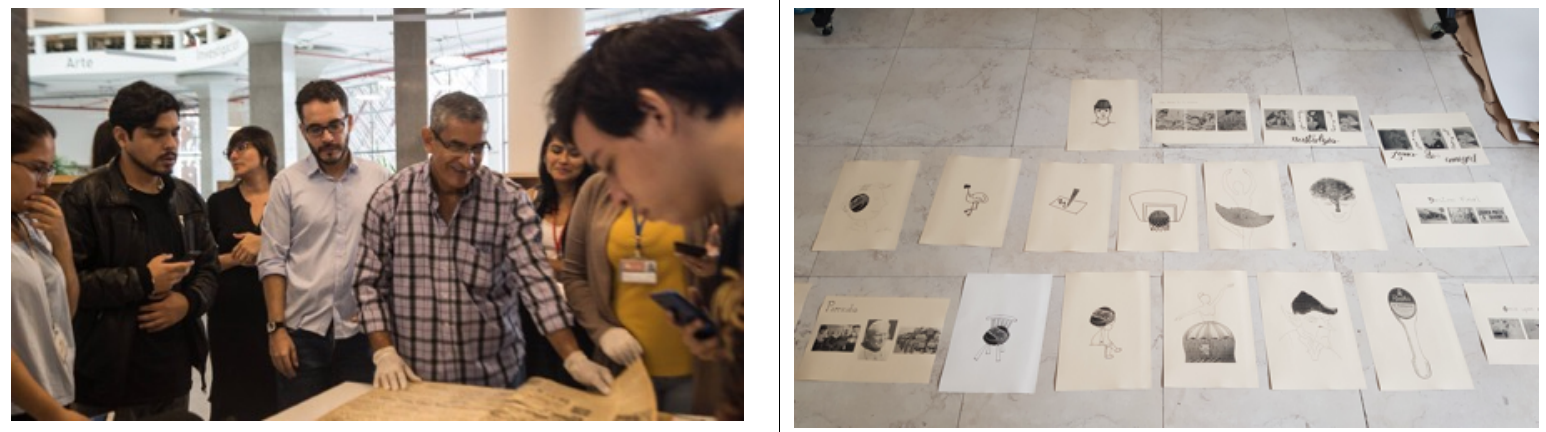

Figura 7 y 8. Reinaldo Rodríguez, custodio del Archivo El Telégrafo, mostrando ejemplares e ilustraciones hechas por los talleristas que guio el artista Javier Pérez. Fotografías Otras Derivas DIY.

\section{Prácticas artísticas - Exposición Mapeando el Archivo}

En las deliberaciones sobre los talleres siempre estuvo presente el concepto de deriva, por eso era desafiante concretar unas exploraciones individuales que propiciarán el cierre del 
proyecto colectivo. Así fue como concebimos una exposición llamada Mapeando el Archivo que tuviera como sede las instalaciones de la Biblioteca de las Artes, donde aglutinaríamos propuestas transdisciplinares para hacer una (re)lectura de un archivo histórico, enfrentando su fragilidad y su valor en la ciudad-puerto. Las cuatro obras creas por el equipo de investigación son: "Serie Desastres Naturales" de Cristian Villavicencio, "Ojos cerrados" de Aurora Zanabria, "Escrito en piedra” de Juan Carlos Fernández y "Aeropostal” de Janina Suárez Pinzón. Esta actividad quedó pospuesta debido a la pandemia global del Covid-19, esperamos concluir la producción de la exposición en el año 2021.

"Serie Desastres Naturales" analiza la visualidad y la pérdida de información de los negativos, los cuales pasan a ser un testimonio material del transcurrir. La "preservación histórica" que es uno de los objetivos del Archivo El Telégrafo queda supeditado a la realidad de desvanecimiento de la "memoria" debido a los fortuitos "desastres" que ha sufrido a lo largo del tiempo (figura 9). Durante la investigación se evidenció que muchos de los negativos que sufrieron daños pertenecen a la categoría “Desastres Naturales”. La obra está compuesta de diversas cajas de luz con un sistema lumínico programado y reactivo al tránsito del público, que mostrará y ocultará una selección de negativos e imágenes digitalizadas que aluden a varias catástrofes que ha atravesado el Ecuador durante la década de los noventa y dos mil.

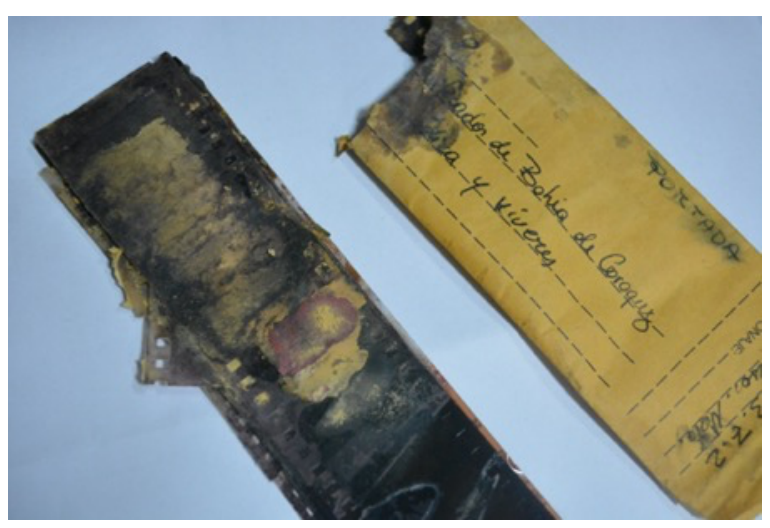

Figura 9. Material damnificado por circunstancias fortuitas en las instalaciones del Archivo El Telégrafo. Fotografías Otras Derivas DIY. 
"Ojos cerrados" es una serie de 50 fotografías de 25 x 11 centímetros. A través de la digitalización de los negativos de la caja "Varios 1" (figura 10). C, que contiene imágenes del acontecer político, social y cultural de Guayaquil y del país, se cuestiona la importancia que tiene la imagen a la hora de contar una historia. En las imágenes solo podemos ver los “ojos” de quienes están retratados por lo que se nos habla de la información faltante en el Archivo, de las historias incompletas. Al mismo tiempo los ojos cerrados son un guiño simbólico de esa realidad que no se quiere ver, de la ausencia, de la poca visibilidad y del no reconocimiento de nuestro pasado en una ciudad que le ha dado la espalda a su memoria y en donde el vacío de políticas institucionales marca nuestro presente y futuro.

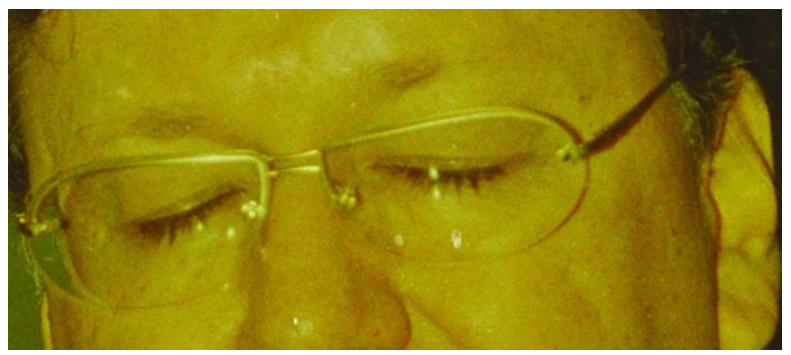

Figura 10. Detalle de obra "Ojos Cerrados", imagen de Marco Vinicio Ruiz, presidente del Consejo Nacional Empresarial para el Tratado de Libre Comercio Centroamérica-Estados Unidos. Tomada el 11 de julio de 2004. Fotografías Otras Derivas DIY.

"Escrito en piedra" consiste en reproducir a gran escala caricaturas ilustradas por V. Jaime Salinas, quien trabajó en El Telégrafo, para evidenciar el carácter lúdico, satírico y frontal del artista, siendo una especie de tributo al aporte de su propuesta gráfica muchas veces minimizada en el ámbito artístico local (figura 11). La obra hace una analogía con la época actual, de una manera asincrónica, a partir de la información rescatada de la revista Semana Gráfica, en su columna La Actualidad en Monos, de los años 1931 y 1932; el objetivo es no alterar el contenido de las caricaturas pues la pretensión es "preservar el patrimonio" y a su vez que dichas imágenes generen una sensación de extrańeza en el espectador. Una vez terminada la exposición la obra será destruida, borrada o cubierta con pintura como un ejercicio de devolverle la historicidad a las imágenes. 


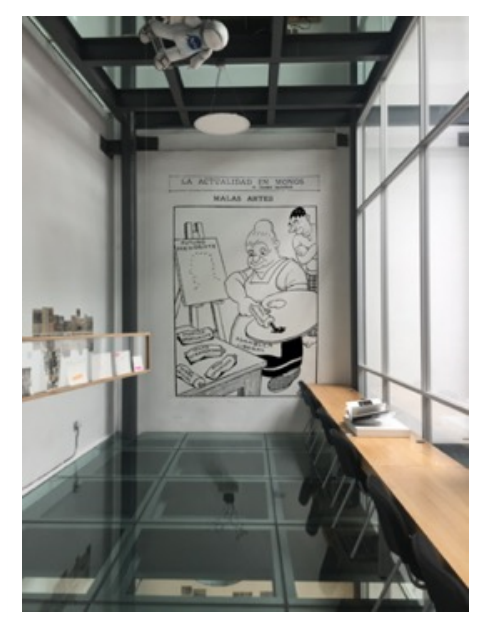

Figura 11. Boceto de una caricatura que conformará la obra "Escrito en Piedra" de Juan Carlos Fernández. Fotografías Otras Derivas DIY.

Para la última obra, "Aeropostal" se revisó la carpeta "Trabajadores de El Telégrafo" para adentrarnos en la realidad habitual de empleados que consagraron su vida hasta su despido o jubilación de la empresa, demostrando integridad, fiabilidad y capacidad para hacer que funcione un sistema de comunicaciones. Desde la sala de redacción a las áreas administrativas aquellas personas vigilaron, editaron, fueron curadores y artífices de los registros, documentación y demás elementos que constituyen el acervo del periódico. Su lealtad da sentido a una serie conmemorativa de diez matasellos como un testimonio visual del talento humano del Decano de la Prensa Nacional. La emisión de los matasellos coincidía con el centenario del "Primer Correo Aéreo del Ecuador", ocurrido en 1920 cuando el biplano El Telégrafo I cruzó los Andes piloteado por el italiano Elia Liut (figura 12). Por este motivo, la instalación incluye una réplica de un avión Macchi Hanriot HD 1 como una alegoría de efemérides ecuatoriana del transporte de la primera valija postal aérea, así como de la primera escuela de aviación y de la independencia de Cuenca, porque la visión de José Abel Castillo, propietario del rotativo porteño, era viabilizar el traslado de ejemplares a todas las regiones del país. 


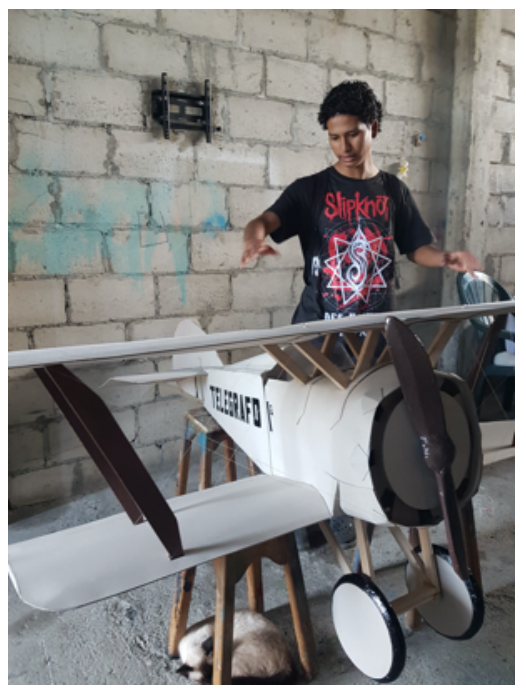

Figura 12. Biplano co-creado con el estudiante Miguel León (UArtes) que compone la instalación "Aeropostal" de Janina Suárez Pinzón. Fotografías Otras Derivas DIY.

En lo correspondiente a las cuatro obras de la exposición Mapeando el Archivo se puede decir que tiene un impulso archivístico constante que mira el adentro y el afuera de la historia escrita y del presente, de las conexiones y desconexiones que suscita la información de El Telégrafo, en alguna medida insinúa una transgresión con imágenes tildadas de desechables. En palabras de Hal Foster (1996) "el artista como archivero recurre a materiales históricos menores, en un eje diacrónico de investigación”. Desde la melancolía de un negativo destruido e incompleto al rearmado del enigma, de la escena o desde el personaje caricaturesco Juan Pueblo, surgido en 1918, para ser el vocero de la calle con sutil ironía denunciando la explotación y opresión. Lo que hace eco en Tello (2015) "al subvertir el ordenamiento del archivo o al exhibir de forma divergente sus sistemas de operación mediante los mismos medios en que estos se llevan a cabo, la práctica artística es capaz de crear nuevas formas de subjetivación" (p. 141). Y por último una instalación para recrear lo afectivo, memorias de personajes aparentemente secundarios en el imaginario colectivo pero que sin sus voluntades hubiese sido dificultosa la utopía de la dirección de la prensa. Sintetizando como investigadores y mediadores del Archivo El Telégrafo ofrecimos interpretaciones alternativas para establecer 
una crítica a las narraciones lineales del patrimonio y a su utilización dentro de un discurso nacional (Carrillo, 2019).

\section{Referencias}

Breakell, S. (2008). Perspectives: Negotiating the Archive. En Tate Papers No.9 Spring 2008.

Carrillo, A. (2019) Metodología, interpretación y archivo: una perspectiva de las potencialidades del arte sobre las lecturas del pasado. Ponencia presentada durante la inauguración del Archivo Histórico El Telégrafo, Biblioteca de las Artes.

Foster, H. (1996). Artista como etnógrafo en The Return of the Real. Cambridge, MA: MIT Press.

Foster, H. (2004). An Archival impulse. En October 110, pp. 3-22. MIT Press.

Guasch, A. (2012). El giro de la memoria y el giro del archivo en las prácticas artísticas contemporáneas. Revista 180, No.29, pp 2-5. Recuperado de: http://www.revista180.udp.cl/index.php/revista180/article/view/93

Hidalgo, A.E. (2017) Recuperación de fuentes primarias para la historia de la arquitectura y el urbanismo de Guayaquil. AUC Revista de Arquitectura No.38, pp 19-29.

Jácome. J. (2019). Entre el arte y las derivas de la comunicación. Texto socializado vía email con el grupo Otras Derivas DIY.

Ketelaar, E. (2003). Being Digital in People's Archives. En Archives \& Manuscripts vol. 31 \# 2, pp. 8-22.

Rodríguez, A. (2018). Un martes cualquiera. Sycorax. Recuperado de: http://proyectosycorax.com/un-martes-cualquiera/ 
Suárez, J. (2019) Las Otras Derivas del Archivo. En Archivomancia El camino del archivomante. Editorial Raza Andina del Colectivo Central Dogma y Sociedad Anómica.

Tamayo, N. (2018) El Telégrafo de Guayaquil y los hechos del 15 de noviembre de 1922: La Prensa como actor político en Ecuador. Americanía. Revista de Estudios Latinoamericanos. Nueva Época (Sevilla), No. 7, pp. 137-158.

Tello, A. (2015) El arte y la subversión del archivo. Aisthesis, No.58, pp.125-143.

Tobar, K. (s/f). En Fundación BilbaoArte Fundazioa. Recuperado de: https://bilbaoarte.org/Artists/karla-tobar/

Enviado: 2021-03-10

Aceptado: 2021-05-03 